\title{
Behavioral and Neurotransmitter Changes in the Urease-Infused Rat: A Model of Congenital Hyperammonemia
}

\author{
MARK L. BATSHAW, SUSAN L. HYMAN, E. DAVID MELLITS, GEORGE H. THOMAS, \\ RICHARD DEMURO, AND JOSEPH T. COYLE \\ Departments of Pediatrics, Psychiatry and John F. Kennedy Institute, Johns Hopkins University School of \\ Medicine, Baltimore, Maryland 21205
}

\begin{abstract}
Rats implanted with subcutaneous or intraperitoneal osmotic minipumps infusing 0.8-1.25 IU urease/ $\mathrm{kg} / \mathrm{h}$ develop sustained hyperammonemia (range 137-497 $\mu \mathrm{M}$, controls $88 \pm 51 \mu \mathrm{M} \pm \mathrm{SD}$ ) for 5-7 days. Glutamine levels are also significantly elevated in plasma $(677 \pm 166$ versus $428 \pm 122 \mu \mathrm{M})$ and cerebral cortex $(13.2 \pm 9.8$ versus $4.7 \pm 2.8 \mathrm{nmol} / \mathrm{mg}$ tissue). Neurobehavioral abnormalities include decreased food intake and increased stereotypic activity. Increased serotonin turnover was suggested by elevated levels of tryptophan and 5-hydroxyindoleacetic acid in cerebral cortex, brain stem, and cerebellum of urease-infused compared to sham-operated animals. There were no changes in norepinephrine or $\gamma$ aminobutyric acid, and there was no correlation between the degree of hyperammonemia or glutaminemia and brain levels of tryptophan or biogenic amines. Animals receiving a tryptophan-deficient diet had significantly lower levels of tryptophan and 5-hydroxyindoleacetic acid in brain regions compared to animals receiving a normal tryptophan intake, under both control and hyperammonemic conditions. Despite the prevention of increased serotonin flux in hyperammonemic animals receiving a tryptophan-deficient diet, food intake and weight declined and there was increased stereotypic behavior. (Pediatr Res 20: 1310-1315, 1986)
\end{abstract}

\section{Abbreviations}

Trp, tryptophan

Trp (-), tryptophan-deficient diet

Trp (+), diet containing adequate Trp

HIAA, 5-hydroxyindoleacetic acid

5-HT, serotonin

GABA, $\gamma$-aminobutyric acid

NE, norepinephrine

ANOVA, analysis of variance

ANCOVA, analysis of covariance

Inherited deficiencies have been described for each of the five enzymes in the urea cycle. Affected children have hyperammonemia associated with elevations in plasma glutamine and alanine levels. Plasma ammonium levels three to four times normal are associated with anorexia, irritability, increased activity levels, pain insensitivity, and sleep disturbances. Higher levels lead to vomiting, lethargy, and coma. Despite effective therapy combin-

Received June 10, 1986; accepted July 31, 1986

Correspondence Mark L. Batshaw, M.D., John F. Kennedy Institute, 707 N. Broadway, Baltimore, MD 21205

This work was supported by USPHS Grants MH40691 and HD10981. ing protein restriction with the stimulation of alternate pathways of waste nitrogen excretion (1) many affected children are mentally retarded and display chronic feeding problems including anorexia and food refusal (2).

These behavioral abnormalities also have been associated with increased serotonin metabolism (3). We have previously reported increased cerebrospinal fluid levels of the metabolite of serotonin, HIAA in a 6-yr-old girl with argininosuccinic aciduria who was anorectic and had a sleep disturbance (4). We have since found elevated cerebrospinal fluid HIAA levels (greater than 2 SD above the mean for age) in four of five other anorectic children with urea cycle disorders (Hyman SL, Batshaw ML, unpublished observations).

Because the rate limiting step in serotonin synthesis, tryptophan hydroxylase, is not saturated at ambient Trp concentrations, brain serotonin turnover is a function of dietary Trp intake and brain Trp transport (5). Our attempt to treat the child with argininosuccinic aciduria using a Trp-restricted diet was successful in lowering cerebrospinal fluid Trp and HIAA levels and in improving appetite and sleep pattern (4).

Herein, we pursue these observations in an animal model of hyperammonemia, the urease-infused rat. Urease induces hyperammonemia by hydrolyzing urea to two ammonium ions and carbon dioxide. A single intraperitoneal injection of urease produces hyperammonemia lasting $8-20 \mathrm{~h}$ in mice, rats, and ferrets (6-8). Repeat injections at 12 -h intervals have been used to maintain hyperammonemia for up to 3 days (7). The hyperammonemia is accompanied by elevated plasma glutamine levels, increased Trp transport into the brain and increased brain serotonin turnover (7).

We have developed a method of producing a constant infusion of urease using osmotic minipumps, extending the duration of hyperammonemia to 5-7 days. Using this approach, we have asked three principal questions: 1) Does experimental hyperammonemia lead to alterations in feeding behavior and activity level? 2) Is there a correlation between hyperammonemia induced behavioral abnormalities and serotonin metabolism? 3) Can the behavioral abnormalities be improved by tryptophan restricted diets?

Our studies show that experimental hyperammonemia is associated with increased serotonin turnover and behavioral alterations including anorexia and stereotypic behavior. However, unlike the pilot human study, a decrease in serotonin flux produced by a Trp-restricted diet was ineffective in changing the behavioral abnormalities.

\section{METHODS}

Biochemical methods. Plasma ammonium levels were measured by a microfluorometric adaptation of a glutamate dehydro- 
genase method (9). A Turner fluorometer with a $365 \mathrm{~nm}$ excitation filter and a $470 \mathrm{~nm}$ emission filter was used. Heparinized blood was obtained by venipuncture from a warmed tail vein. The blood was immediately placed on ice and ammonium levels assayed within $30 \mathrm{~min}$. The assay mixture was comprised of: $0.08 \mathrm{mM}$ NADPH, $152 \mathrm{mM}$ triethanolamine buffer at $\mathrm{pH} 8.6$, $15.2 \mathrm{mM}$ alpha ketoglutarate, $1.52 \mathrm{mM}$ NADP (BoehringerMannheim). One-half $\mathrm{ml}$ of this mixture, $1.5 \mathrm{ml}$ ammonium free water, and $0.05 \mathrm{ml}$ plasma was combined and a fluorometric reading taken after a 10 -min equilibration period. Five $\mu 1$ glutamate dehydrogenase $(750 \mathrm{U} / \mathrm{ml}$, Boehringer-Mannheim) was added and a second reading was taken $10 \mathrm{~min}$ later. Ammonium chloride standards of $50,100,200$, and $300 \mu \mathrm{M}$ were used. The change in absorbance was linear between $0-300 \mu \mathrm{M}$. Samples with higher concentrations were diluted.

Plasma, obtained by venipuncture from a warmed tail vein, was stored at $-4^{\circ} \mathrm{C}$ for amino acid analysis and brain was stored at $-80^{\circ} \mathrm{C}$. Cerebral cortex ( $200 \mathrm{mg}$ diluted $1: 3$ ) was homogenized in a $0.1 \mathrm{~N}$ sodium acetate buffer, $\mathrm{pH}$ 4.95. Amino acids in plasma and brain were measured following precipitation with $5 \%$ sulfosalicylic acid by automated ion exchange column chromatography using a Beckman 6300 high pressure amino acid analyzer. Tryptophan was measured separately by an adaptation of an HPLC method with fluorometric detection (10) using a Kratos flow-through fluorometer with a $254 \mathrm{~nm}$ excitation filter, $340 \mathrm{~nm}$ emission cutoff filter, and FSA 113 lamp. The mobile phase consisted of a phosphate buffer $(0.02 \mathrm{M} \mathrm{KH} 2 \mathrm{PO} 4$, pH 4.0) with $10 \%$ acetonitrile. Plasma was precipitated with trichloroacetic acid and the $\mathrm{pH}$ adjusted to 4.0. Tryptophan in brain was measured directly on homogenates prepared as noted below.

Biogenic amines in brain were determined by an adaptation of an HPLC method with electrochemical detection (11) using a Waters system with an Environmental Sciences Associates electrochemical detector set at $0.35 \mathrm{~V}$ and a $\mathrm{C} 18$ reverse phase column (Brownlee Labs). The mobile phase consisted of sodium acetate $0.01 \mathrm{mM}(\mathrm{pH} 4.0)$, disodium EDTA $0.05 \mathrm{mM}$, and heptane sulfonate $9 \mathrm{mM}$ with $4 \%$ acetonitrile. The mobile phase was run at $1.0 \mathrm{ml} / \mathrm{min}$ and the run time was $40 \mathrm{~min}$. Injection volume was 15 ul. Brain tissue (30 mg diluted $1: 20$ ) was homogenized in a $0.1 \mathrm{~N}$ sodium acetate buffer, $\mathrm{pH} 4.95$. Ascorbate oxidase $(1700 \mathrm{U} / \mathrm{mg}$, Sigma) $6.7 \mu \mathrm{g} / \mathrm{ml}$ was added to the homogenate in order to eliminate the ascorbate peak. The limits of detection for biogenic amines were (pmol/mg tissue) NE, 0.09; HIAA, 0.09; and 5-HT, 0.50. We also measured levels of dopamine and homovanillic acid. However, approximately onequarter of these values fell below the limits of detection of our method, $0.26 \mathrm{pmol} / \mathrm{mg}$ tissue. Thus, these data were not exposed to statistical analysis.

Urease activity was measured in pumps prior to implant and then in pumps removed from animals 3-7 days following implant. Fluid was aspirated from these pumps and urease activity measured by the spectrophotometric method of Schlegel and Kaltwasser (12). Residual urease activity was defined as activity at 3-7 days/initial activity; the result was expressed as a percent.

Animal studies. Male Sprague-Dawley rats weighing 250-300 $\mathrm{g}$ were placed in individual cages on $12 \mathrm{~h}$ light $/ 12 \mathrm{~h}$ dark cycles for a 5-7-day baseline period. They had free access to pellets prepared from an amino acid mixture (13) (U. S. Biochemical Corporation), $\mathrm{g} / \mathrm{kg}$ pellets: L-Ala 3.5, L-Arg 11.2, L-Asn 6.0, LAsp 3.5, L-Cys 3.5, L-Glu 35.0, Gly 23.3, L-His 3.3, L-Ile 8.2, L-Leu 11.1, L-Lys 14.4, L-Met 8.2, L-Phe 11.6, L-Pro 3.5, L-Ser 3.5, L-Thr 8.2, L-Trp 1.75, L-Tyr 3.5, L-Val 8.2. This mixture also contained vitamin supplements, a salt mixture, and had a caloric content of $4.4 \mathrm{cal} / \mathrm{g}$. An osmotic minipump (Alzet 2001/ 2002) was then implanted subcutaneously or intraperitoneally under chloral hydrate/pentobarbital anesthesia. The minipump contained Jackbean urease (Sigma, type VI) in sterile $\mathrm{NaCl} 0.9 \%$, providing $0.8-1.25 \mathrm{IU} / \mathrm{kg} / \mathrm{h}$ (1 IU urease $=0.088$ Sigma units = $1 \mu \mathrm{mol}$ ammonia released per min at $\mathrm{pH} 7.0$ at $25^{\circ} \mathrm{C}$.) A paired group of animals received sham operations. There was no surgical mortality. However, preliminary assessment of infusions of urease 1.6-2.0 IU $/ \mathrm{kg} / \mathrm{h}$ resulted in marked hyperammonemia (range $390-960 \mu \mathrm{M}$, mean $560 \mu \mathrm{M}, n=10$ ) and an $80 \%$ mortality rate during the first $48 \mathrm{~h}$ after implantation. Following surgery the animals were either placed back on the complete amino acid mix or on the same mix with L-Trp left out of the mixture.

Weights and food intake were measured daily during the study. Physical activity levels were measured using a Digiscan Animal Activity Monitor (Omnitech Model RXYZCM) with acrylic cages $(14,15)$. Motor activity was detected by infrared light beam sensors located 2 inches apart above the perimeter of the monitor. Measures included distance moved, speed, rest time, vertica movements, and stereotypic behavior. Stereotypic behavior is defined as the number of times the monitor observed the animal breaking the same beam repeatedly. An interrupt interval of at least $1 \mathrm{~s}$ was required to separate one stereotypic movement from the next. Stereotypes included sniffing, licking, gnawing, and rearing behaviors. An initial training session was followed by 12-h nighttime sessions during the baseline period and 3 days after urease implant.

The animals studied for biogenic amines were decapitated in a nonfasting state and without anesthesia in the morning 3-7 days postimplantation. The brains were dissected within 2 min on a cooled plate into five regions: cerebellum, cortex, brainstem, thalamus, and hypothalamus (16)

Statistical analysis. For analysis of plasma ammonium and amino acid levels, the standard $t$ statistic for between group differences was used following natural $\log$ transformations. Postpre comparisons used the paired form of the $t$ test. As a result of multiple comparisons, instead of considering $p<0.05$ to be significant, only $p$ values $<0.025$ were considered to be significant. For brain biogenic amines and Trp concentrations an ANOVA was performed on the natural $\log$ transformations in the four study groups: urease, Trp+; urease, Trp-; sham, Trp+; Sham, Trp-. This analysis utilized the $2 * 2$ factorial arrangements of these groups in order to examine the effect of Trp withdrawal from feed, the effect of hyperammonemia and their interaction (orthogonal contrasts) (17). Polynomial regression was utilized to test for the possible relationship between degree of hyperammonemia and level of HIAA and Trp in various brain regions. Analyses of food intake were compared using ANCOVA performed on the values during infusion, adjusted for values prior to infusion. For motor activity only three groups of animals were tested (sham Trp+, urease Trp+, urease Trp-). Therefore, analysis of differences between group means were performed by the multiple comparisons technique of Tukey (17).

\section{RESULTS}

We initially examined whether urease infusion could produce an appropriate model of congenital hyperammonemia. Figure 1 shows the changes in plasma ammonium levels and urease activity in rats implanted with 7-day osmotic minipumps infusing $0.8-1.25 \mathrm{IU} / \mathrm{kg} / \mathrm{h}$. There was a 3 - to 6 -fold rise in ammonium levels during the first 3 days of infusion. Levels remained elevated, although at a lower level, for 5 days and then fell to normal. This was reflected by a progressive decrease in residual urease activity measured in pumps removed from animals between 3-7 days. A similar decline in activity was found in urease solutions incubated in vitro at $37^{\circ} \mathrm{C}$ for 7 days (data not shown).

Plasma levels of ammonium, amino acids and GABA were obtained prior to infusion and 3 days postimplant in shamoperated and urease-infused animals. Preinfusion levels were similar in both groups. Table 1 shows that plasma ammonium and glutamine levels were significantly higher, $p<0.001$, during urease infusion as compared to sham-operated animals. There was no significant difference between groups in any other amino acid including branched-chain amino acids and tryptophan or in GABA. 
Table 1 also shows levels of amino acids and GABA in cortex of urease-infused and sham-operated animals. Concentrations of glutamine, alanine, and histidine were significantly higher in urease infused as compared to sham-operated animals. There was no significant difference in other amino acids or in GABA.

As with intraperitoneal implants, subcutaneous implantation of 7-day urease containing osmotic pumps resulted in hyperammonemia, $230 \pm 128 \mu \mathrm{M}(n=12)$. There was a gradual decline

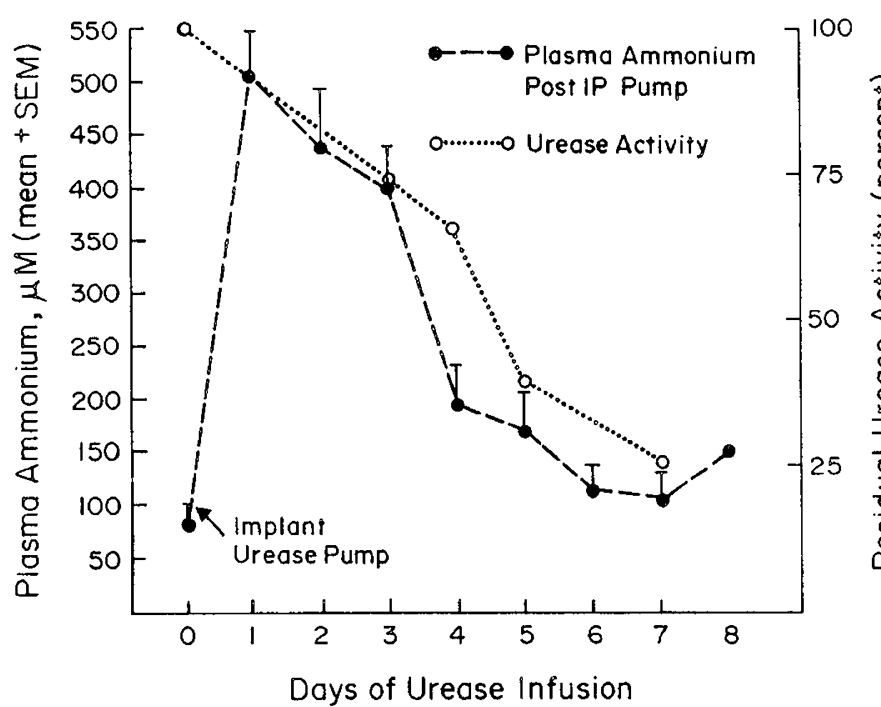

Fig. 1. Plasma ammonium levels in 24 rats following peritoneal implantation of 7-day osmotic minipump infusing 0.8-1.25 $\mu \mathrm{MU}$ urease/ $\mathrm{kg} / 24 \mathrm{~h}$ ). Also shown is the mean residual urease activity in pumps removed from three animals each at 3-7 days. in ammonium levels over 5 days. Subcutaneous implantation of a second pump at 5 days resulted in a second briefer peaking of plasma ammonium, $406 \pm 270 \mu \mathrm{M}$ (Fig. 2).

Having demonstrated that urease infusion leads to hyperammonemia and elevated glutamine levels, we next evaluated the effects of these metabolic derangements on feeding behavior and activity. Figure 3 illustrates the changes in food intake and weight with intraperitoneal urease infusions compared to sham operated animals during the first 3 days of infusion. The urease-infused animals ate less, $p<0.001$, and lost more weight, $p<0.02$, than the sham-operated animals. Carrying this analysis to 4 days

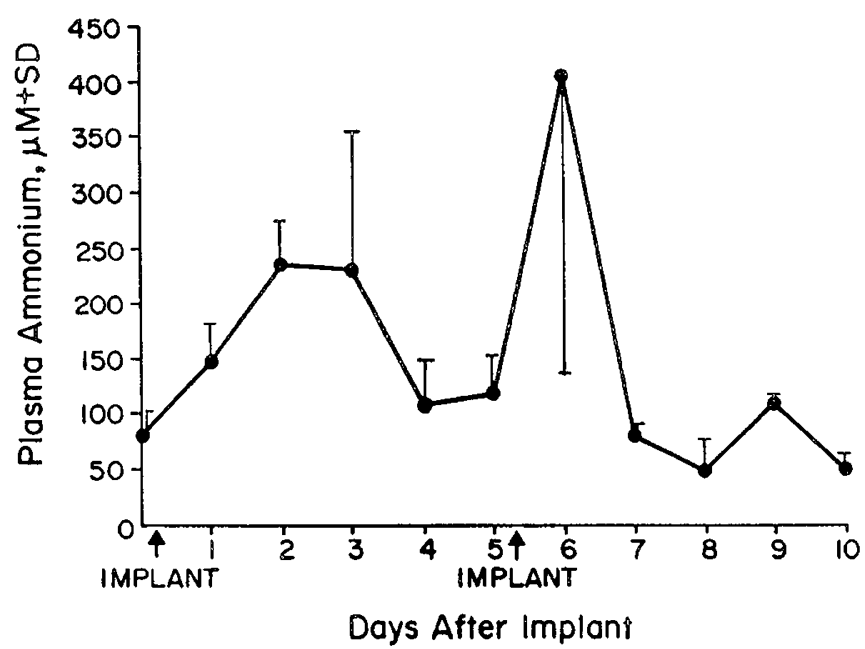

Fig. 2. Plasma ammonium levels $(n=12)$ following subcutaneous urease implants at 0 and 5 days.

Table 1. Ammonium, amino acids, and GABA 3 days postperitoneal implant (mean $\pm S D$ )

\begin{tabular}{|c|c|c|c|c|}
\hline & \multicolumn{2}{|c|}{ Plasma $(\mu \mathrm{M})$} & \multicolumn{2}{|c|}{ Cortex (nmol/mg tissue) } \\
\hline & Sham $(n=13)$ & Urease $(n=14)$ & Sham $(n=7)$ & Urease $(n=8)$ \\
\hline $\mathrm{NH}_{4} \dagger$ & $63 \pm 17$ & $390 \pm 131^{*}$ & & \\
\hline Taurine & $328 \pm 109$ & $305 \pm 144$ & $4.43 \pm 0.42$ & $4.50 \pm 0.59$ \\
\hline Aspartic acid & $22 \pm 8$ & $18 \pm 11$ & $2.60 \pm 0.40$ & $2.24 \pm 0.29$ \\
\hline Threonine & $543 \pm 223$ & $537 \pm 230$ & $1.23 \pm 0.57$ & $0.45 \pm 0.37$ \\
\hline Serine & $504 \pm 173$ & $447 \pm 187$ & $1.20 \pm 0.21$ & $1.24 \pm 0.34$ \\
\hline Asparagine & $61 \pm 32$ & $69 \pm 20$ & $\mathrm{ND} \dagger$ & ND \\
\hline Glutamic acid & $78 \pm 51$ & $67 \pm 50$ & $7.64 \pm 2.29$ & $7.21 \pm 1.14$ \\
\hline Glutamine & $428 \pm 122$ & $677 \pm 166^{*}$ & $4.73 \pm 2.77$ & $13.19 \pm 9.76 \ddagger$ \\
\hline Proline & $99 \pm 94$ & $81 \pm 84$ & $0.11 \pm 0.03$ & $0.29 \pm 0.22$ \\
\hline Glycine & $1005 \pm 406$ & $906 \pm 403$ & $1.19 \pm 0.18$ & $1.14 \pm 0.30$ \\
\hline Alanine & $512 \pm 158$ & $398 \pm 163$ & $0.79 \pm 0.14$ & $2.42 \pm 1.72 \ddagger$ \\
\hline Citrulline & $69 \pm 31$ & $88 \pm 26$ & $0.02 \pm 0.01$ & $0.03 \pm 0.02$ \\
\hline Valine & $118 \pm 52$ & $115 \pm 31$ & $0.35 \pm 0.02$ & $0.28 \pm 0.17$ \\
\hline Cystine & $22 \pm 15$ & $28 \pm 14$ & $0.07 \pm 0.02$ & $0.12 \pm 0.90$ \\
\hline Methionine & $72 \pm 25$ & $73 \pm 20$ & $0.15 \pm 0.06$ & $0.24 \pm 0.13$ \\
\hline Isoleucine & $64 \pm 18$ & $56 \pm 13$ & $0.12 \pm 0.05$ & $0.22 \pm 0.16$ \\
\hline Leucine & $94 \pm 24$ & $76 \pm 19$ & $0.24 \pm 0.12$ & $0.53 \pm 0.44$ \\
\hline Tyrosine & $93 \pm 28$ & $93 \pm 25$ & $0.18 \pm 0.09$ & $0.33 \pm 0.20$ \\
\hline Phenylalanine & $67 \pm 20$ & $75 \pm 12$ & $0.16 \pm 0.10$ & $0.29 \pm 0.19$ \\
\hline GABA & $5 \pm 4$ & $3 \pm 3$ & $3.08 \pm 0.90$ & $2.75 \pm 0.61$ \\
\hline Tryptophan & $37 \pm 16$ & $36 \pm 16$ & $0.39 \pm 0.15$ & $0.47 \pm 0.22^{*}$ \\
\hline Ornithine & $43 \pm 11$ & $49 \pm 12$ & $0.04 \pm 0.01$ & $0.06 \pm 0.03$ \\
\hline Lysine & $557 \pm 171$ & $486 \pm 153$ & $0.24 \pm 0.05$ & $0.38 \pm 0.22$ \\
\hline Histidine & $57 \pm 22$ & $80 \pm 28$ & $0.11 \pm 0.02$ & $0.30 \pm 0.23 \ddagger$ \\
\hline Arginine & $159 \pm 54$ & $178 \pm 48$ & $0.19 \pm 0.07$ & $0.22 \pm 0.13$ \\
\hline
\end{tabular}

$* p<0.001$ comparing sham to urease infused.

$\uparrow$ Not detected.

$\ddagger p<0.025$ comparing sham to urease infused. 


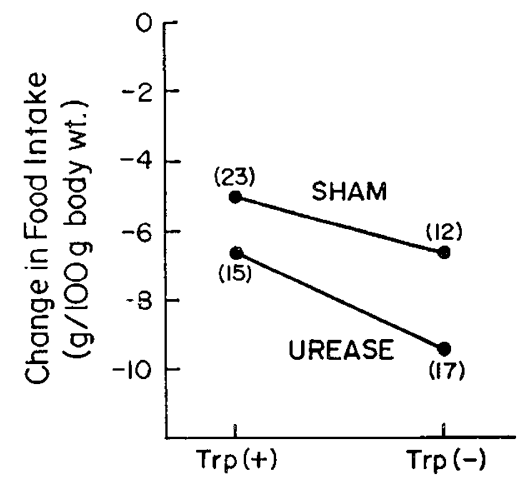

Treatment Condition

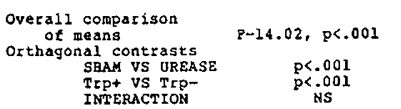

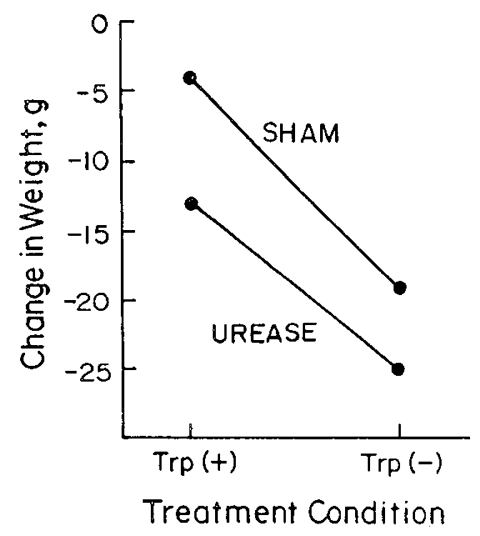

$p=13.02, p<.001$
$p<.02$
$p<.002$

Fig. 3. Mean change in food intake and in weight during the first 3 days of urease infusion and in sham animals under normal Trp+ and Trpdiets. Number of animals in parentheses.

Table 2. Mean change in 12-h motor activity (3 days post-pre implant) in urease-infused and sham animals

\begin{tabular}{lccc}
\hline & Sham Trp+ $(n=16)$ & Urease Trp+ $(n=9)$ & Urease Trp- $(n=9)$ \\
\hline Distance (in) & -57 & +186 & -105 \\
Rest time (s) & -26 & +128 & +101 \\
Speed (in/h) & +1.2 & -5.1 & +2.2 \\
Vertical time (s) & +40 & -121 & -100 \\
Stereotypies (n) & +0.9 & $+8.2^{*}$ & $+39.6^{*}$ \\
\hline
\end{tabular}

${ }^{*} \mathrm{~F}=3.95, p<0.03$.

showed a similar difference between groups. Thus, although the largest change in food intake and weight loss occurred shortly after implant, the effects persisted at least for 4 days. The effects of a Trp-depleted diet on food intake and weight are discussed below.

Motor activity was measured in a computerized activity box prior to and 3 days after implant in three groups: sham Trp+, urease $\operatorname{Trp}+$, and urease Trp-. Table 2 shows changes in distance moved, rest time, speed, stereotypic behavior, and vertical movement during 12-h nighttime sessions comparing post- to preurease infusion. Analysis of variance on the change in motor activity showed a significant increase in stereotypic behavior in the urease infused groups compared to sham. Clinically the animals did not exhibit neurologic abnormalities unless ammonium levels rose above $500 \mu \mathrm{M}$ at which point they became lethargic, wandered in circles, and pressed their heads against the cage before becoming comatose.

We then studied the effect of hyperammonemia on brain biogenic amines. Table 3 shows levels of biogenic amines in various brain regions of urease infused animals sacrificed while hyperammonemic between 3-7 days postimplant $(317 \pm 180$ $\mu \mathrm{M}$ in urease infused Trp+ and $389 \pm 175 \mu \mathrm{M}$ in urease infused Trp-) and in sham-operated controls. Trp and HIAA levels were significantly elevated in the cortex, brain stem, and cerebellum of hyperammonemic animals. Levels of NE and serotonin were not significantly different between groups in any brain region. Polynomial regression was performed to determine if there was a relationship between plasma ammonium or glutamine levels and the levels of tryptophan and biogenic amines in brain. There was no significant correlation found between the degree of hyperammonemia, 200-600 $\mu \mathrm{M}$, or hyperglutaminemia (438-981 $\mu \mathrm{M})$ and levels of Trp or biogenic amines in the various brain regions. There was also no correlation found between cortical levels of glutamine and Trp or biogenic amines. The level of stereotypic activity was not correlated with cortical HIAA levels.

We also studied the effect of Trp-diet on the changes in brain
Trp, biogenic amines, and feeding behavior in hyperammonemic and sham rats. It should be noted that plasma Trp levels in both Trp- groups were significantly lower than the respective Trp+ group $(\mu \mathrm{M} \pm \mathrm{SD})$ : sham Trp-, $16 \pm 7(n=18)$; sham Trp,+ 37 $\pm 16(n=13) p<0.001$; urease Trp-, $23 \pm 12(n=20)$; urease Trp+, $36 \pm 16(n=14) p=0.01$. In both urease and sham animals receiving a Trp- diet, HIAA levels were significantly lower in all brain regions and Trp was lower in cortex and cerebellum compared to the respective group receiving a Trp+ diet (Table 3 ). There was a positive linear correlation between Trp intake and cortical $\operatorname{Trp}(r=0.49, p<0.01)$ and HIAA levels $(r=0.59, p<0.01)$ in the sham animals. There was no interaction found either between the Trp-diet or hyperammonemia on HIAA and Trp concentration; i.e. the effects of hyperammonemia and increased tryptophan intake were additive. There were no consistent findings in other biogenic amines. Food intake (Fig. 3) was also significantly lower and weight loss greater in both Trp- groups compared to their respective Trp+ group; no interaction between the effects of hyperammonemia and Trp intake could be demonstrated by one-way ANOVA.

To examine the effect of a low, but not deficient, Trp intake on serotonin metabolism and food intake, a small group of rats received the minimum daily requirement of $\operatorname{Trp}, 0.2 \mathrm{mmol} / \mathrm{kg} /$ day, either during urease infusion $(n=6)$ or sham conditions $(n$ $=6$ ). As in the previous experiments, HIAA levels in cortex were higher in the urease infused group $(3.41 \pm 1.53 \mathrm{pmol} / \mathrm{mg})$ as compared to the sham-operated animals $(2.30 \pm 0.49 \mathrm{pmol} / \mathrm{mg})$. Similarly, Trp levels in cortex were higher in the urease infused group, $48.0 \pm 7.5$ versus $36.7 \pm 4.0 \mathrm{pmol} / \mathrm{mg}$. However, compared to the sham Trp+ animals (receiving $0.5 \mathrm{mmol} \mathrm{Trp} / \mathrm{kg} /$ day), the urease infused, low Trp animals did not have a significant increase in cortical levels of either HIAA or Trp (Table 3). Despite the prevention of evidence of increased brain serotonin flux using a low Trp diet in urease-infused animals, there was no amelioration of weight loss, $-20.6 \pm 15 \mathrm{~g}$ compared to $-4 \pm 1$ $\mathrm{g}$ in sham Trp+ animals, $p<0.001$. 
Table 3. Concentration of biogenic amines in brain regions of animals sacrificed 3-7 days postimplant [pmol/mg tissue (overall $S D)]$

\begin{tabular}{|c|c|c|c|c|}
\hline & $\begin{array}{c}\text { Sham Trp+ } \\
(n=26)\end{array}$ & $\begin{array}{l}\text { Sham Trp- } \\
(n=23)\end{array}$ & $\begin{array}{l}\text { Urease Trp+ } \\
\quad(n=18)\end{array}$ & $\begin{array}{l}\text { Urease Trp- } \\
\quad(n=28)\end{array}$ \\
\hline \multicolumn{5}{|l|}{ Cortex } \\
\hline $\mathrm{NE}(0.77)$ & 2.40 & 2.55 & 3.34 & 2.40 \\
\hline HIAA $(0.59)$ & 3.30 & 1.56 & 4.25 & 2.86 \\
\hline $5-\mathrm{HT}(0.62)$ & 1.02 & 1.32 & 1.67 & 1.43 \\
\hline $\operatorname{Trp}(0.41)$ & 39.3 & 25.0 & 46.5 & 42.3 \\
\hline \multicolumn{5}{|l|}{ Thalamus } \\
\hline NE (0.63) & 5.05 & 4.64 & 4.84 & 4.96 \\
\hline HIAA $(0.97)$ & 6.55 & 2.29 & 7.01 & 4.85 \\
\hline 5-HT $(0.63)$ & 1.58 & 1.23 & 2.20 & 1.52 \\
\hline \multicolumn{5}{|l|}{ Brain stem } \\
\hline NE $(0.71)$ & 3.13 & 3.66 & 3.43 & 3.53 \\
\hline HIAA $(0.83)$ & 4.54 & 2.12 & 6.08 & 3.17 \\
\hline $5-\mathrm{HT}(0.55)$ & 1.50 & 1.51 & 1.66 & 1.69 \\
\hline $\operatorname{Trp}(0.64)$ & 34.6 & 33.6 & 77.9 & 50.6 \\
\hline \multicolumn{5}{|l|}{ Hypothalamus } \\
\hline $\mathrm{NE}(1.35)$ & 10.9 & 7.47 & 8.30 & 7.26 \\
\hline HIAA $(0.76)$ & 5.58 & 2.01 & 5.49 & 4.01 \\
\hline $5-\mathrm{HT}(0.77)$ & 2.10 & 1.79 & 2.96 & 2.00 \\
\hline \multicolumn{5}{|l|}{ Cerebellum } \\
\hline NE (0.59) & 1.17 & 1.40 & 1.46 & 1.39 \\
\hline HIAA $(0.83)$ & 1.01 & 0.43 & 1.52 & 1.02 \\
\hline Trp $(0.54)$ & 35.1 & 20.1 & 49.0 & 39.4 \\
\hline
\end{tabular}

Statistical significance

\begin{tabular}{|c|c|c|c|c|c|}
\hline \multirow[b]{2}{*}{ Brain region } & \multirow{2}{*}{\multicolumn{2}{|c|}{$\begin{array}{c}\text { Overall differences } \\
\text { ANOVA }\end{array}$}} & \multicolumn{2}{|c|}{ Orthogonal contrasts } & \multirow[b]{2}{*}{ Interaction } \\
\hline & & & Sham $v s$ urease & $\operatorname{Trp}+v s \operatorname{Trp}-$ & \\
\hline Cortex & $\begin{array}{l}\text { HIAA } F=15.19 \\
\operatorname{Trp} F=9.04\end{array}$ & $\begin{array}{l}p<0.001 \\
p<0.001\end{array}$ & $\begin{array}{l}\text { HIAA } p<0.001 \\
\operatorname{Trp} p<0.001\end{array}$ & $\begin{array}{l}\text { HIAA } p<0.002 \\
\operatorname{Trp} p<0.002\end{array}$ & NS \\
\hline Thalamus & HIAA $F=6.21$ & $p<0.001$ & NS & HIAA $p<0.001$ & NS \\
\hline Brain stem & $\begin{array}{l}\text { HIAA } F=11.28, \\
\operatorname{Trp} F=3.18\end{array}$ & $\begin{array}{l}p<0.001 \\
p<0.05\end{array}$ & $\begin{array}{l}\text { HIAA } p<0.05 \\
\text { Trp } p<0.005\end{array}$ & HIAA $p<0.001$ & NS \\
\hline Hypothalamus & HIAA F $=7.20$ & $p<0.001$ & $\mathrm{NA}^{*}$ & HIAA $p<0.001$ & NS \\
\hline Cerebellum & $\begin{array}{l}\text { HIAA F }=8.86 \\
\operatorname{Trp} F=10.01\end{array}$ & $\begin{array}{l}p<0.001 \\
p<0.001\end{array}$ & $\begin{array}{l}\text { HIAA } p<0.002 \\
\operatorname{Trp} p<0.001\end{array}$ & $\begin{array}{l}\text { HIAA } p<0.001 \\
\operatorname{Trp} p<0.001\end{array}$ & NS \\
\hline
\end{tabular}

* Not available.

\section{DISCUSSION}

A number of experimental models have been developed to study the effects of elevated plasma ammonium levels on metabolism, neurochemistry, and behavior of various animal species. These include the genetic mutant sparse-fur mouse (18), infusions of ammonium salts or organic acids $(19,20)$, the use of arginine-deficient diets (21), and the injection of urease (6).

The urease-infused rat provides a useful model to study congenital hyperammonemia as, unlike portocaval shunt models (22), there is hyperammonemia associated with increased glutamine levels while plasma branched chain amino acids and Trp are unchanged. The use of osmotic minipumps permits a constant infusion of urease, prolonged hyperammonemia, and allows behavioral observations that would not be possible with an external constant infusion apparatus. A limitation is the 7-14 day life of the infusion pumps and the inactivation of urease at body temperature over time. Another potential problem of longterm infusions is the development of antibodies to urease (23). This could explain the briefer duration of hyperammonemia following the second subcutaneous urease implant.

The neurobehavioral consequences of urease-induced hyper- ammonemia have been varied. Gibson et al. (24) reported that mice administered a single intraperitoneal dose of urease, 2.2 $\mathrm{IU} / \mathrm{kg}$, wandered in circles, were ataxic, and pressed their heads against the side of the cage. We did not observe similar symptoms in rats at urease infusions of $0.6-1.25 \mathrm{IU} / \mathrm{kg} / \mathrm{h}$, but we did observe ataxia, coma, and an $80 \%$ mortality at infusions of 1.6 $2.0 \mathrm{IU} / \mathrm{kg} / \mathrm{h}$ with ammonium levels above $500 \mu \mathrm{M}$. The variability in clinical response of different animal species is exemplified by the ferret which does not exhibit clinical symptoms until plasma ammonium levels of $2000 \mu \mathrm{M}$ are reached (8).

Although there were no severe neurologic alterations in our hyperammonemic animals (plasma ammonium $<500 \mu \mathrm{M}$ ), there was increased stereotypic behavior compared to control animals. Stereotypic behavior is defined as repetitive actions that have no purpose; this may resemble stereotypic behavior seen in children with chronic hyperammonemia and mental retardation. Feeding patterns were also disrupted by urease infusion. The hyperammonemic rats ate less and lost more weight than the control animals.

We studied the neurochemical correlates of hyperammonemia to test the hypothesis that increased serotonin turnover exists and is associated with decreased food intake. The postulated 
mechanism would involve serotonin input to the ventromedial hypothalamus (25). This rationale was suggested by the work of Bachmann and Colombo (7) who have shown, in urease-injected rats, significant increases in brain uptake of Trp and increased HIAA, Trp, and other large neutral amino acids in forebrain and brain stem. We find similar increases of Trp and HIAA levels in cortex, cerebellum, and brain stem under hyperammonemia induced by urease infusion. There was no correlation between the degree of hyperammonemia and the increase in Trp and HIAA levels in brain. This is more consistent with a threshold effect for increase Trp transport into the brain than a gradient effect. Concentrations of serotonin, norepinephrine, and GABA were not altered.

The mechanism of increased Trp transport across the blood brain barrier is unclear but may involve elevated brain glutamine levels (26). Our studies confirm elevated glutamine levels in brain during urease induced hyperammonemia. However, there was no correlation between plasma or cortical glutamine levels and levels of HIAA and Trp. Other investigators have shown that increased brain Trp transport is blocked in hyperammonemic animals by the glutamine synthetase and glutamyl cysteine synthetase inhibitor, methionine sulfoximine (27).

We also studied whether the prevention of increased brain Trp and HIAA levels would ameliorate the anorexia and stereotypic behavior associated with hyperammonemia. Hyperammonemic animals receiving either the minimum daily requirement of Trp or no Trp did not exhibit increased brain Trp and HIAA levels in brain. Despite this, the animals who received a diet with low or absent Trp content ate less, lost more weight, and had increased stereotypic behavior compared to the respective group receiving a normal Trp intake. There was no interaction found between the individual effects of Trp intake and plasma ammonium levels on brain Trp, HIAA, food intake, and weight loss; i.e. the effects of ammonium and dietary Trp were additive. This lack of interaction makes sense teleologically. By decreasing its food intake, the hyperammonemic animal limits its caloric supply. This leads to reduced insulin secretion and increased branched-chain amino acid levels which compete with Trp for uptake into the brain (28). Thus, the effect of hyperammonemia on increasing brain Trp uptake would be blunted by the decreased food intake. This effect would be amplified by a diet low in Trp content.

The lack of a behavioral response of experimental hyperammonemia to a Trp-restricted diet is at variance with our pilot study of a patient with a urea cycle disorder. This child did respond to a Trp-restricted diet with improved feeding behavior (4). This may indicate that the results in our one patient cannot be generalized to other affected individuals; alternatively there may be differences between the chronic human disease and the more acute experimental hyperammonemia that explain the discrepant results.

In summary, the infusion of urease by osmotic minipump is a useful model to study the effects of hyperammonemia on brain function and behavior. It is associated with hyperammonemia and elevated glutamine levels. Behavioral changes include anorexia and increased stereotypic activity. Neurochemical alterations involve increased brain Trp transport and increased serotonin flux. Hyperammonemia-induced anorexia and stereotypic behaviors did not respond to a Trp-restricted diet under the conditions studied.

Acknowledgments. The authors acknowledge the help in statistical analysis provided by Rosemary Baumgartner and Dr. Alan Ross, aid in the setting up of the behavioral studies by Drs. Timothy Moran and Kenneth Kubos, advice on biogenic amine analysis by Dr. Robert Zaczek, and the secretarial assistance of Susan Cascio.

\section{REFERENCES}

1. Batshaw ML, Brusilow SW, Waber L, Blom W, Brubakk AM, Burton BK Cann HM, Kerr D, Mamunes P, Matalon R, Myerberg D, Schafer IA 1982 Treatment of inborn errors of urea synthesis: activation of alternative pathways of waste nitrogen synthesis and excretion. N Engl J Med 306:13871392

2. Hyman SL, Porter CA, Page TJ, Iwata BA, O'Brien S, Kissel RC, Crist K, Batshaw ML 1986 Operant approaches in the treatment of feeding disorders in inherited urea cycle Pediatr Res 20:162A

3. Young SN 1986 The clinical psychopharmacology of tryptophan in Wurtman RJ, Wurtman JJ (eds) Nutrition and the brain. Raven Press, New York, NY, pp 49-88

4. Hyman SL, Coyle JT, Parke JC, Batshaw ML 1986 Anorexia and altered serotonin metabolism in a patient with argininosuccinic aciduria. $J$ Pediat 108:705-709

5. Hamon M, Bourgouin F, Artaud F, El Mestikawy S 1980 The respective roles of tryptophan uptake and tryptophan hydroxylase in the regulation of serotonin synthesis in the central nervous system. J Physiol (Paris) 77:269279

6. Dang MC, Visek WJ 1964 Some effects of urease on laboratory animals. Am J Physiol 206:731-737

7. Bachmann C, Colombo JP 1983 Increased tryptophan intake into the brain in hyperammonemia. Life Sci 33:2417-2424

8. Deshmukh DR, Shope TC 1983 Arginine requirement and ammonia toxicity in ferrets. J Nutr 113 1664-1667

9. Nazar BL, Schoolwerth AC 1979 An improved microfluorometric enzymatic assay for the determination of ammonia. Anal Biochem 95:507-511

10. Anderson GM, Young JG, Batter DK, Young SN, Cohen DJ, Shaywitz BA 1981 Determination of indoles and catechols in rat brain and pineal using liquid chromatography with fluorometric and amperometric detection. J Chromatogr 223:315-320

11. Zaczek R, Coyle JT 1982 Rapid and simple method for measuring biogenic amines and metabolites in brain homogenates by HPLC-electrochemical detection. $\mathbf{J}$ Neurol Transm 53:1-5

12. Schiegel HG, Kaltwasser H 1974 Urease. In: Bergmeyer HU (ed) Methods of Enzymatic Analysis. Academic Press Inc., New York, NY, pp 1081-1085

13. Rogers QR, Harper AE 1965 Amino acid diets and maximal growth in the rat J Nutr 87:267-273

14. Sanberg PR, Moran TH, Kubos KL, Coyle JT 1983 Automated measurement of stereotypic behavior in rats. Behav Neurosci 97:830-832

15. Moran TH, Sanberg PR, Kubos KL, Goldrich M, Robinson RG 1984 Asymmetrical effects of unilateral cortical suction lesions: behavioral characterization. Behav Neurosci 98:747-752

16. Glowinski J, Iverson LL 1966 Regional studies of catecholamines in the rat brain. The disposition of $[3 \mathrm{H}]$ dopamine and $[3 \mathrm{H}]$ DOPA in various regions of the brain. J Neurochem 13:655-669

17. Snedecor GW, Cochran WG 1980 Statistical Methods, 7th ed. Iowa State University Press, Ames, IA, pp 298-333

18. DeMars R, LeVan SL, Trend BL, Russell LB 1976 Abnormal ornithine carbamyl transferase in mice having the sparse-fur mutation. Proc Natl Acad Sci USA 73:1693-1697

19. Hindfelt B 1973 The effect of acute ammonia intoxication upon the energy state of the brain in rats pretreated with L-methionine D-L-sulphoximine (MSO). Scand J Clin Lab Invest 31:289-299

20. Stewart PM, Walser M 1980 Failure of the normal ureagenic response to amino acids in organic acid-loaded rats. Proposed mechanism for the hyperammonemia of propionic and methylmalonic acidemia. J Clin Invest 66:484-492

21. Morris JG, Rogers QR 1978 Ammonia intoxication in near-adult cat as a result of a dietary deficiency of arginine. Science 199:431-432

22. Jones EA, Mullen KD, Jones DB 1986 The encephalopathy of hepatic failure In: Coyle JT (ed) Animal Models of Dementia. Allan R. Liss, Inc. New York, NY (in press)

23. Visek WJ, lwert ME, Nelson NS, Rust JH 1967 Some immunologic properties of jackbean urease and its antibody. Arch Biochem Biophys 122:95-104

24. Gibson GE, Zimber A, Krook L, Richardson EP, Visek WJ 1974 Brain histology and behavior of mice injected with urease. J Neuropathol Exp Neurol 33:201-21

25. Morley JE 1980 The neuroendocrine control of appetite: the role of the endogenous opiates, cholecystomines, TRH, gamma-aminobutyric acid and the diazepam reception. Life Sci 27:355-368

26. Gorgievski-Hrisoho M, Colombo JP, Bachmann C 1986 Stimulation of tryptophan uptake into brain microvessels by D-glutamine. Brain Res 367:395397

27. Bachmann C 1985 Brain tryptophan uptake and glutamine synthetase in hyperammonemia rats. Hoppe Seylers Z Physiol Chem 364:1255-1256

28. Fernstrom JD 1985 Dietary effects on brain serotonin synthesis: relaltionship to appetite regulation. Am. J Clin Nutr 42:1072-1082 